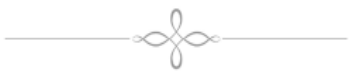

\title{
Abordagens geográficas sobre as praças da área central da cidade de Poços de Caldas (MG)
}

Antonia Marcia Duarte

Queiroz*

Rosselvelt José Santos**

Resumo: Este trabalho objetiva discutir sobre a geografia urbana na área central da cidade de Poços de Caldas - MG. O foco da análise se volta para a categoria "lugar" tendo como objeto de estudo as praças. A análise qualitativa foi um suporte importante na metodologia, pois se utilizou de pesquisa de campo, para observação, entrevistas e aquisição de imagens. Nesse sentido, também se reflete, sobre a importância da praça como patrimônio cultural/natural na área central da cidade de Poços de Caldas, pois estas contribuem para as relações sociais na formação da cidade. As relações sociais, tanto de ordem social, como econômica, política e cultural, são as formas expressas da interação e construção dos lugares centrais urbanos.

\section{Geographical approaches on the squares of the city of Poços de Caldas (MG)}

\begin{abstract}
This work aims to discuss on the urban geography in the central area of the city of Poços de Caldas-MG. the focus of the analysis is back to the category "place" taking as object of study the squares. Qualitative analysis was an important support in the methodology, as field research was used for observation, interviews and image acquisition. In this sense, is reflected on the importance of cultural/natural heritage square in the city of Poços de Caldas, as these contribute to social relations in the formation of the city. Social relations, both social, economic, political and cultural as, are ways expressed the interaction and construction of central urban places.
\end{abstract}

* Mestre em Desenvolvimento Social pela Universidade Estadual de Montes Claros (UNIMONTES). Doutoranda em Geografia na Universidade Federal de Uberlândia (UFU) Bolsista CAPES.

** Doutor em Geografia Universidade de São Paulo (USP). Professor Titular no Instituto de Geografia da UFU.

Palavras-chave:

Cidade; Geografia; praças.

Key-Words:

City; Geography, squares. 


\section{Área central; as praças patrimônio cultural/natural urbano}

De acordo com Correa (1995) a área central constitui- se no foco principal não apenas da cidade, mas também de sua hinterlândia. Nela concentram - se as principais atividades comerciais, de serviço, da gestão pública e privada, e os terminais de transportes inter-regionais e intra -urbanos. Ela se destaca na paisagem da cidade pela sua verticalização. A gênese da área central. A cidade mantém uma série de relações com entes e pessoas exteriores a ela.

O surgimento da área central foi percebido de forma nítida com a Revolução Industrial. O grande aumento de produtos industrializados gerou a necessidade de uma malha de transportes que suprisse a crescente demanda, dando ensejo à construção das grandes ferrovias. A partir de então se verifica um processo de aglutinação em torno das estações ferroviárias, pelo grande fluxo de pessoas que circulavam destas estações. Os empresários buscavam se estabelecer próximos às massas de pretensos consumidores. Com isto, iniciou-se a aglutinação de investimentos e estabelecimentos em torno destas estações de transportes, delimitando a área central da cidade.

Dentre os setores que compõem o espaço urbano, a área central possui significativa magnitude enquanto forma espacial. Localizada, geralmente na parte mais antiga da cidade, ela é facilmente reconhecida no tecido urbano por uma série de fatores, dos quais se destaca a sua complexidade funcional devido à alta diversidade na concentração de comércio e serviços, a sua acessibilidade, no sentido de que é foco da cidade e da hinterlândia, o alto grau de reestruturação arquitetônica e econômica, cujos fatores são responsáveis por sua valorização, e imponente verticalização.

Não obstante, sobre a importância do centro da cidade enquanto elemento fundamental da estrutura urbana destaca-se que a conceptualização e a identificação desse sítio e de suas diferentes setorizações ainda apresentam-se envoltos em uma nebulosa. Comumentemente verifica-se uma variedade de expressões atribuídas ao centro urbano, como centro principal, centro histórico, hipercentro, algumas utilizadas de forma equivocada. O núcleo central caracteriza-se como o ponto de concentração máxima das atividades de comércio e serviços e, por conseguinte, de infraestruturas, em especial as de comunicação. Por isso, "constitui o ponto onde os preços do solo atingem os valores mais altos, bem como objeto de interesse de diversos atores sociais, o que direta ou indiretamente contribui para a manutenção da supremacia dessa área" (ALVES, 2011, p.62).

As cidades, são consideradas por Lopes (2012) como expressão material das relações sociais que nela ocorrem, não são formações recentes. Desde seu surgimento até a contemporaneidade, as cidades sofreram modificações consideráveis, tanto em suas formas como em suas funções, de acordo com os interesses da sociedade que ocupava o território e da maneira como esta se reproduzia no espaço.

[...] a partir do final do século XIX, com o adensamento populacional urbano e tendo em vista o desenvolvimento de atividades comerciais e a formação de uma "sociedade de consumo", o espaço urbano sofre intensas alterações em sua organização interna, especialmente a partir da aglomeração de atividades terciárias em uma área especifica da cidade. Essa concentração ocorre na chamada Área Central local de mais fácil acesso dentro do espaço urbano, onde se concentram fluxos de pessoas, mercadorias, informações e meios de transporte (LOPES, 2012, p.37).

Geografia Ensino \& Pesquisa, v. 18, n.3, p. 27-36, set./dez. 2014

Abordagens geográficas sobre as praças da área central da cidade de Poços de Caldas (MG)
A partir desse contexto da área central, optou-se para desenvolver o objeto de estudo, a praça por meio das análises de Lauande Junior (2008), as quais afirmam que muitas são as interpretações do que vem a ser uma praça como espaço urbano tornando-se difícil encontrar entre os estudiosos uma mesma definição.

Na Grécia chamava-se Ágora, era um espaço político; em Roma, espaço comercial; as praças medievais eram atividades sociais cotidianas e comerciais; no Renascimento a partir do século XV e XVI, foram incorporadas às praças intenções simbólicas; no século XVIII, as praças assumem características capitalistas mercantis; no século XIX surgem interesses das classes dominantes e a separação dos espaços públicos e privados, as praças tornam-se lugares de passagem e o conceito 
de ajardinadas com a transição do capitalismo mercantil para o industrial; no século XX, a cidade modernista assume a praça como articuladora do tecido urbano. No Brasil, as praças seguem a orientação européia com adaptações locais e prosseguem a partir do século XIX com a vinda da família real, sob a orientação da linha clássica francesa.

Lauande Junior (2008) admite que a praça deve ser entendida como qualquer categoria de espaço urbano: o resultado da interação de vários aspectos que emprestam características próprias a um determinado sistema social-temporal, que o produz. É possível afirmar que a cidade é uma expressão espacial da evolução social, pois é através dessa interação que a sociedade modifica a natureza com o intuito de atingir sua satisfação e suas necessidades sociais, econômicas e culturais.

Para Tuan (1983), existem vários tipos de espaços, que podem ser individuais ou grupais onde são vividas as experiências do "outro". Considera ainda, o espaço mítico-conceitual, pois extrapola para além da evidência dos sentidos em direção a estruturas mais abstratas. Afirma que o lugar se constitui quando o espaço se torna familiar para a pessoa, o que denomina como espaço vivido da experiência.

Tuan (1983) afirma que há alguns sentimentos e atitudes relacionados ao lugar que podem ser: 1) topofilia refere-se àquele que tem apego ao lugar, se sente seguro; 2) topofobia está relacionado àquele que apresenta aversão a algum lugar específico; 3) topocídio é a destruição do lugar; e 4) topo-reabilitação é a restauração, a recuperação do lugar.

Archela (2004) aponta que podemos compreender 'lugar' como algo inacabado e que está num processo de constante alteração, aberto e em movimento. Daí a necessidade de ampliar o entendimento do vivido para o concebido. Analisa as diferentes maneiras como as pessoas sentem e conhecem o espaço e o lugar.

Segundo Vaz (2006) um lugar não constitui um mero contentor ou um simples ponto no espaço, mas representa o local de encontro que possibilita aos atores sociais diversos contextos de transação e modos de coexistências e de conflitos, isto significa que o ligar detém, além de contornos físicos, uma dimensão de co-presença humana, ou seja, uma significação simbólica.

Este se torna então, um produto da experiência humana, da própria existência, do seu quotidiano, do envolvimento do indivíduo com o mundo, da necessidade de segurança e de sentir raízes, sociais e biológicas. É um espaço físico conotado socialmente com as relações sociais que se desenrolam.

Os argumentos supracitados serviram de embasamento teórico para análise da área central e lugar na perspectiva da cidade de Poços de Caldas.

\section{Reflexões sobre a importância das praças como patrimônio cultural/natural na área central de Poços de Caldas- MG}

De acordo com Santos (2001) a palavra patrimônio está historicamente associada ou à noção do sagrado, ou à noção e herança, de memória do indivíduo, de bens de família. interesse público impede legalmente que eles sejam destruídos ou mutilados. O ato do tombamento, prerrogativa do poder Executivo, não implica desapropriação e nem determina o uso, tratando-se sim e uma fórmula realista de compromisso entre o direito individual à propriedade e a defesa do interesse público relativamente à preservação de valores culturais.

Santos (2001) assevera que hoje, um dos maiores desafios à gestão do patrimônio cultural é definir conceitual e legalmente novas formas de acautelamento compatíveis com sua abrangência, cada vez maior, e com o exercício dos direitos culturais do cidadão, reconhecidos no texto da Constituição de 1988, particularmente no artigo 215: "O Estado garantirá a todos o pleno exercício dos direitos culturais e acesso às fontes da cultura nacional [...]" e no artigo 216: "O Poder Público, com a colaboração da comunidade, promoverá e protegerá o patrimônio cultural brasileiro, por meio de inventários, registros, vigilância, tombamento e desapropriação, e de outras formas de acautelamento e preservação".

Geografia Ensino \& Pesquisa, v. 18, n.3, p. 27-36, set./dez. 2014

Queiroz, A. M. D.; Santos, R. J. 
no âmbito internacional, e 64 anos no Brasil, o caráter simbólico do patrimônio vem sendo ampliado. A ideia de um patrimônio comum a um grupo social, definidor de sua identidade e enquanto tal merecedor de proteção nasce no final do século XVIII, com a visão moderna de história e de cidade (BABELON e CHASTEL, 1994, Apud. SANTOS, 2001).

Para a autora supracitada no Brasil, a promulgação do Decreto-Lei no 25, de 30 de novembro de 1937, organizou a proteção do patrimônio histórico e artístico nacional e instituiu o instrumento do tombamento. A abrangência conceitual na abordagem do patrimônio cultural está relacionada com a retomada da própria definição antropológica da cultura como tudo o que caracteriza uma população humana ou como o conjunto de modos de ser, viver, pensar e falar de uma dada formação social. Ou, ainda como todo conhecimento que uma sociedade tem de si mesma, sobre outras sociedades, sobre o meio material em que vive e sobre sua própria existência, inclusive as formas de expressão simbólica desse conhecimento através das ideias, da construção de objetos e das práticas rituais e artísticas.

Segundo Santos (2001) apesar de todas as discussões teóricas conduzidas em âmbito internacional, somente em 1982 a UNESCO conseguiu chegar a um acordo sobre a necessidade de uma definição mais abrangente para a cultura, que passa desde então a ser referência: "conjunto de características distintas, espirituais e materiais, intelectuais e afetivas, que caracterizam uma sociedade ou um grupo social [...] engloba, além das artes e letras, os modos de viver, os direitos fundamentais dos seres humanos, os sistemas de valor, as tradições e as crenças" (UNESCO, 2000, apud. Santos, 2001).

Segundo Portas (2006) o espaço, enquanto recurso humano limitado e desigualmente distribuído constitui um local de confronto pela sua apropriação, interpretação e utilização por parte dos atores sociais, em regra inseridos em grupos sociais. O espaço como o tempo constitui uma das condições e eixos inerentes à sociedade humana, por outro, a organização do espaço comporta a marca da ação humana. Conceitos territoriais tais como casa, aldeia ou cidade, região ou país são simultaneamente geográficos e sociológicos. Portas (2006) considera que:

As realidades espaciais constituem não só locais de reprodução social, como também testemunhos da memória coletiva de um agrupamento humano, do seu percurso histórico, das suas vicissitudes e contradições, não só internas como face ao exterior (PORTAS, 2006, p.187).

Nesse sentido, destaca-se que as praças centrais na cidade de Poços de Caldas se tratam de espaços físicos, lugares agradáveis e representativos para a cidade com todas as suas representações e emotividades. Servem como ponto de partida para a análise espacial, pois contribui para o resgate do processo de formação da cidade, revelando as relações entre o homem e a natureza na construção da cidade.

Quanto à concepção de praça, Robba \& Macedo (2003, p.16) afirmam: “a abrangência do termo gera algumas distorções quanto à terminologia dos espaços urbanos [...] para se designar praça o espaço livre deve ser destinado ao lazer da população e ser público". Haja vista, não só a sua importância recreativa, mas também histórica e cultural que está inserida no processo de construção das primeiras cidades e naturalmente as praças.

Destaca-se que no Brasil, o termo praça está associado a qualquer espaço verde público, canteiros centrais e bancos. Ressalta-se que, além disso, para se se caracteriza como tal, as praças para aceitação da população devem conter em sua essência, fatos históricos remanescentes à sua edificação. O qual traduza aos usuários e moradores contemporâneos a sua importância cultural e se constituem em espaços coletivos, cuja vivência do lazer e recreação no cotidiano

Geografia Ensino \& Pesquisa, v. 18, n.3, p. 27-36, set./dez. 2014

Abordagens geográficas sobre as praças da área central da cidade de Poços de Caldas (MG)

30 ISSN 2236-4994 dos moradores garante o exercício pleno da cidadania. Além disso, é um local público no qual reflete a história do lugar, com suas correlações, interpretações e representatividades.

O município de Poços de Caldas - MG, que segundo dados do IBGE (2012) possui cerca de 154.974, habitantes, ocupando uma considerável porção do território no extremo sul do Estado de Minas Gerais. Possui uma das maiores expectativas de vida do Estado. As praças centrais fazem parte da sua formação urbana e do seu contexto de estruturação histórico, econômico e cultural de produção turística. 
Figura 1 - Praça Pedro Sanches- área central- Poços de Caldas-MG

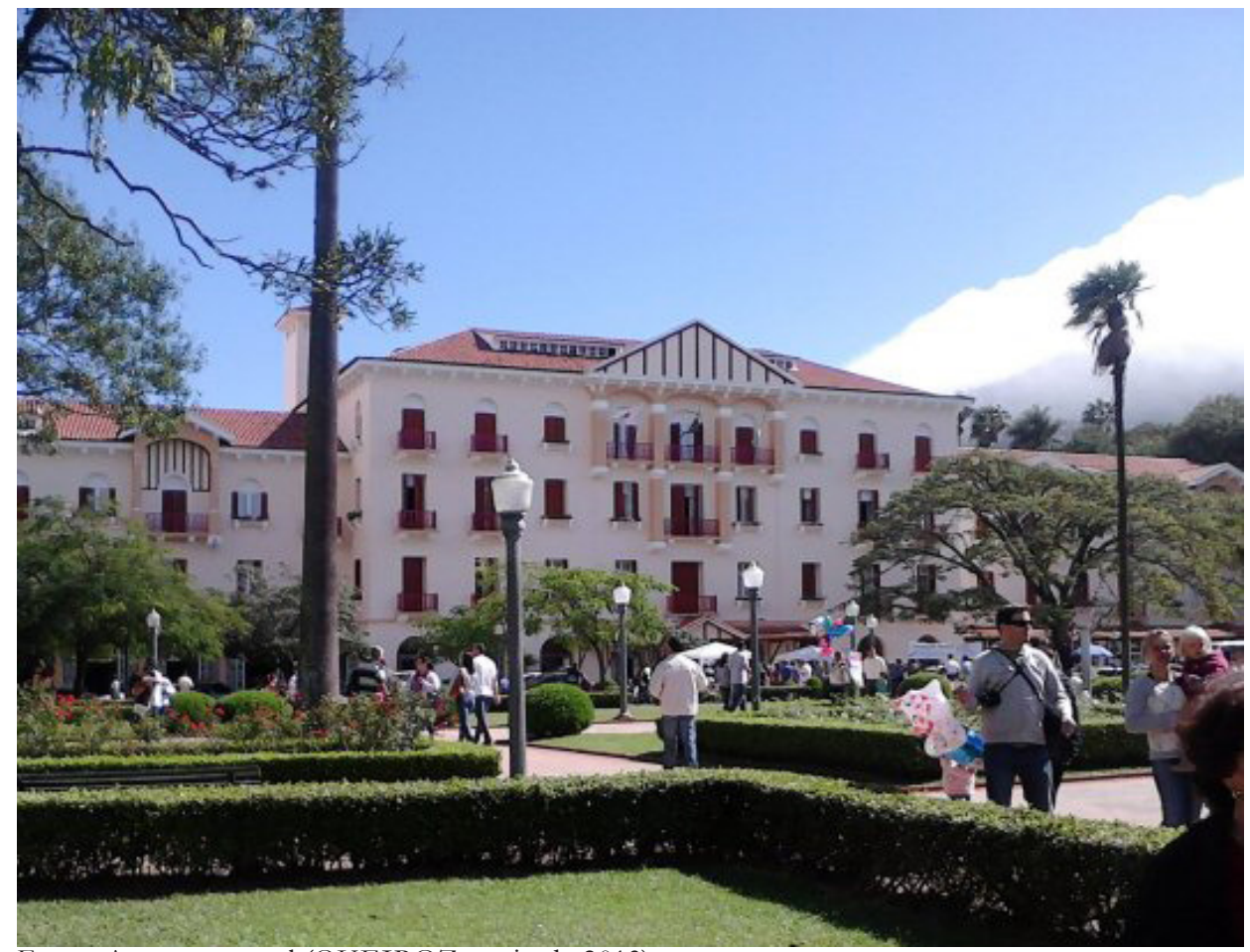

Fonte: Acervo pessoal (QUEIROZ, maio de 2013).

A Figura 1 mostra a Praça Pedro Sanches na área central da cidade de Poços de Caldas, muito importante para o desenvolvimento turístico, pois apresenta o Thermas Antônio Carlos, ao centro dessa praça o Palace hotel com arquitetura europeia e, no seu entorno áreas verdes e fontes naturais.

As praças, enquanto patrimônios identificam-se nas palavras de Drummond (2007) as quais apontam que o urbano é a capital do patrimônio, e se distingue em patrimônio cultural construído pelos humanos e o natural construído maciçamente por processos supra-humanos ou extra-humanos.

Segundo Oliven (2003) o termo patrimônio refere-se a algo que herdamos e que, por conseguinte, deve ser protegido.

De acordo com Gonçalves (2003), usamos também a noção de patrimônios culturais, arquitetônicos, históricos, artísticos, etnográficos, ecológicos, genéticos e intangíveis, de recente formulação no Brasil que insere novas categorias, tais como lugares, festas, religiões, dentre outros. Parece não haver limite para o processo de qualificação dessa palavra.

Abreu (2003) adverte que é preciso, ainda, sublinhar a dimensão que constitui a razão de ser da noção de patrimônio, como herança e legado que se transmite a novas gerações, a dimensão de vida.

De acordo com Sant'Anna (2003), novas e instigantes questões serão colocadas à prática patrimonial tradicional. De início, uma atenção maior ao uso e à prática dos espaços protegidos, mas também, uma ideia de identidade e uma noção de autenticidade mais complexa e dinâmica.

Para demonstrar a importância do patrimônio natural, cultural e intangivel inerente às praças urbanas na cidade de Poços de Caldas, além da Praça Pedro Sanches (Figura 1), destaca-se o contexto da praça central Dom Pedro II "Praça dos macacos" e sua importância patrimonial para a formação da cidade (vide Figura 2).

A Figura 2 mostra uma importante praça na área central de Poços de Caldas, pois de acordo com dados da prefeitura de Poços de Caldas (2013) nessa praça há atividades culturais e mostra de artesanatos, que são produzidos pela população da cidade. Essas exposições acontecem aos sábados, domingos, feriados, principalmente aos finais de semana.

Geografia Ensino \& Pesquisa, v. 18, n.3, p. $27-36$, set./dez. 2014

Queiroz, A. M. D.; Santos, R. J. 
Figura 2 - Praça Dom Pedro II "Praça dos macacos".

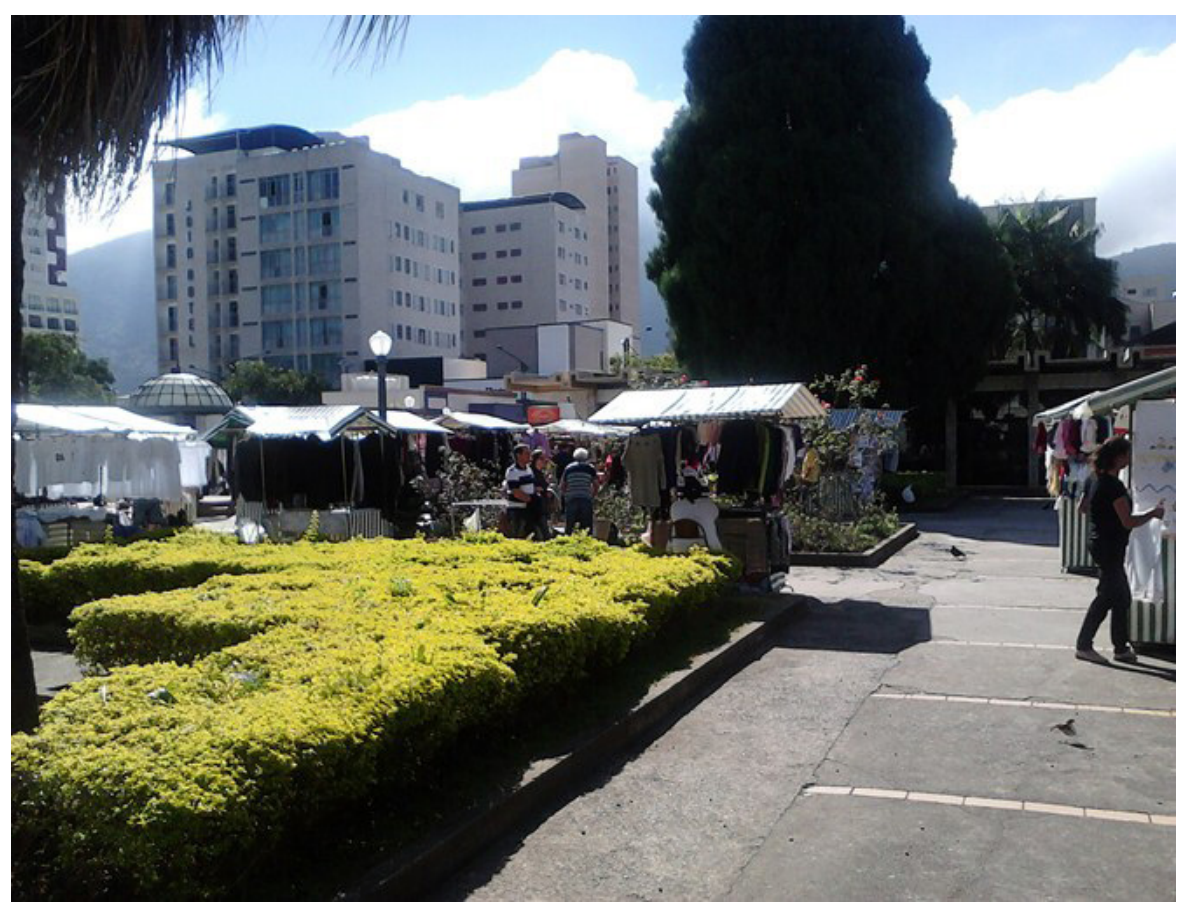

Fonte: Acervo pessoal (QUEIROZ, maio de 2013)

Figura 3 - Praça Dom Pedro II "Praça dos macacos".

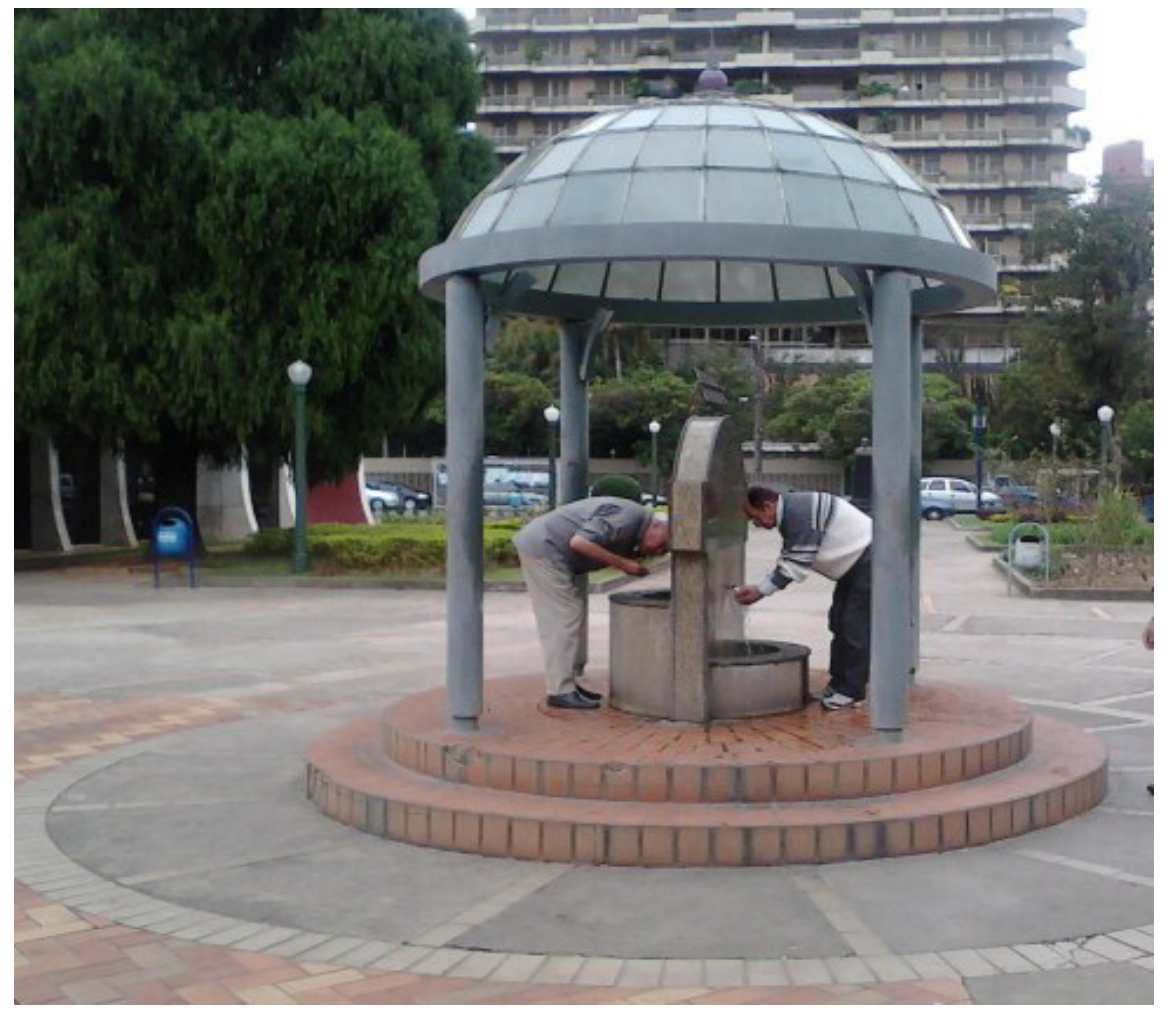

Geografia Ensino \& Pesquisa, v. 18, n.3, p. $27-36$, set./dez. 2014

Abordagens geográficas sobre as praças da área central da cidade de Poços de Caldas (MG)

$32 \quad$ ISSN 2236-4994
Fonte: Acervo pessoal (QUEIROZ, maio de 2013)

A Figura 3 apresenta a Praça -Dom Pedro II, "Praça dos Macacos" por meio das águas sulfurosas e termais, possuem características terapêuticas, possui composição alcalina, bicarbonatada, sulfetada e hipertermal. A água tem forte odor, mas é límpida e brota do solo a uma temperatura de $41 \mathrm{C}^{2}$. Essa fonte natural é muito utilizada pelos moradores locais e turistas.

Nesse sentido, destaca-se a praça, pois se trata de um local representativo para a cidade com todos os seus significados e emotividades. A praça é um local importante nas áreas urbanas que serve 
como ponto de partida, também para a análise espacial que possibilite o resgate do processo de formação da cidade, revelando as relações entre o homem e a natureza na sua construção.

Para Correa (2001) a formação espacial, reside no fato de se explicitar teoricamente que uma sociedade só se torna concreta através de seu espaço, do espaço que ela produz, por outro lado, o espaço é inteligível através da sociedade. "É considerada como um metaconceito, um paradigma, que contém e está contida nos conceitos-chave, de natureza operatória, de paisagem, de região, espaço, lugar e território." (CORRÊA, 2001, p.26,27). Portanto o espaço da praça pode servir para amenizar os impactos urbanos estabelecendo características diferentes do ambiente da cidade, preservando a identidade e referências que a tornaram única.

Santos (2002) considera que as cidades se distinguem uma das outras por fixos e fluxos e mudá-los é mudar a sua própria significação para os próprios moradores, pois a cidade é um fixo enorme e possui fixos econômicos, sociais e culturais.

Assim pode-se afirmar que a praça possui características próprias, onde as relações sociais se desenvolvem em meio ao espaço urbano que é dinâmico, em uma cidade que está sempre mudando, sempre exercendo novas funções. Portanto o espaço da cidade transforma-se, expande-se, exigindo adaptações do lugar e da paisagem (vide Figura 4).

Figura 4 - Praça Getúlio Vargas- área central- Poços de Caldas-MG

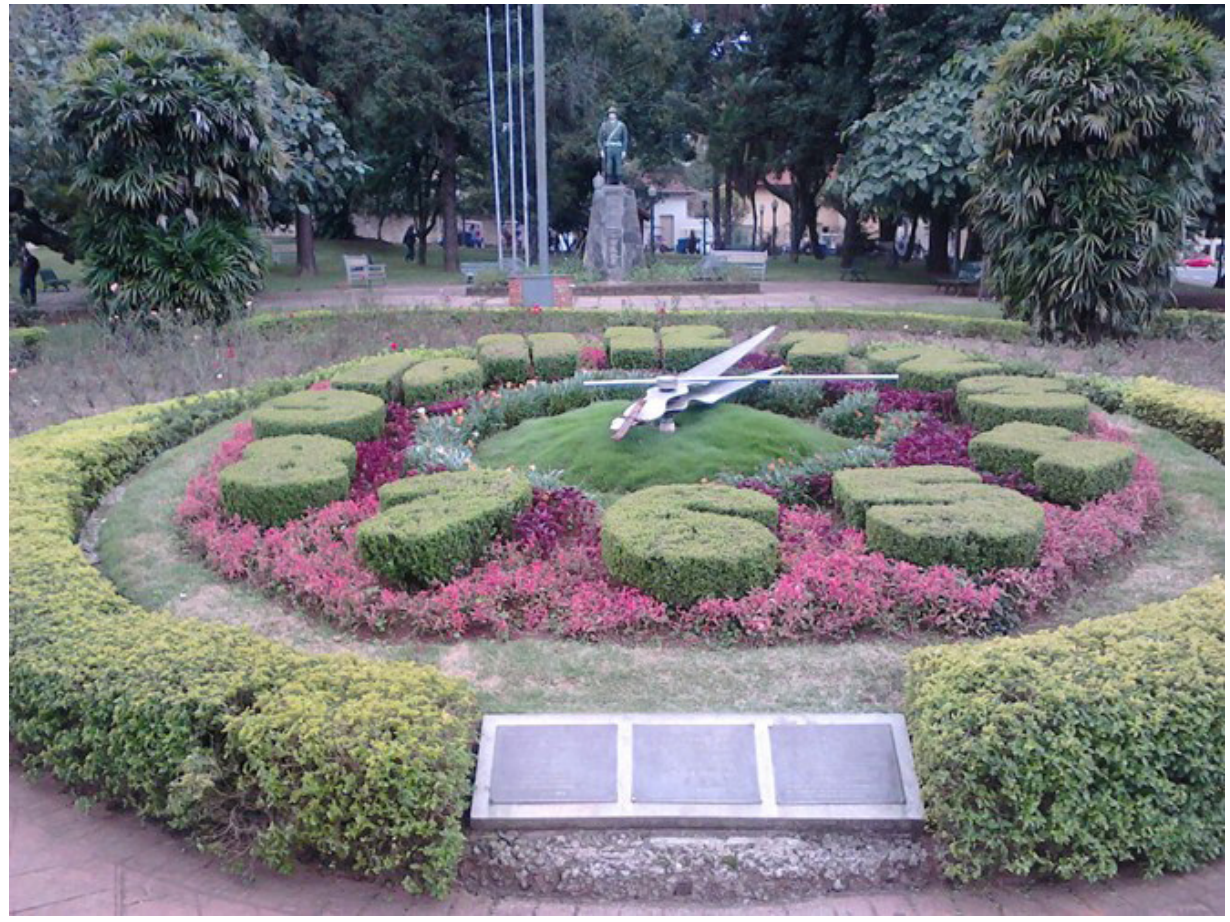

Fonte: Acervo pessoal (QUEIROZ, maio de 2013)

A Figura 4 apresenta a Praça Getúlio Vargas que pode fazer parte do patrimônio da cidade, pela sua característica paisagística transformada pela ação humana, no caso observa-se um relógio natural com ponteiros metálicos artificiais que apresenta, pontualmente, as horas diárias. Essa praça possui localização estratégica na área central da cidade de Poços de Caldas e, em frente ao Espaço Cultural da Urca, onde são realizadas várias atividades culturais, artísticas e intelectuais tanto para a população local quanto para os seus visitantes.

O espaço urbano se modifica e a praça acompanha essas transformações que representam uma nova configuração, onde antigas características desapareceram, em função das adaptações de um novo cenário da praça, seja em âmbito social, econômico, paisagístico, bem como nas concepções ideológicas de lugar.
${ }^{2}$ Fonte de informações: Site oficial da Prefeitura de Poços de Caldas. Disponível em: http://www.pocosdecaldas. mg.gov.br/site/?p=2535. Acesso em junho/ 2013.

Geografia Ensino \& Pesquisa, v. 18 n.3, p. 27-36, set./dez. 2014

Queiroz, A. M. D.; Santos, R. J. 
Calvino (2006) aborda em seu livro As cidades Invisíveis, nomenclaturas femininas para expor suas impressões e representações sobre as cidades e as praças, como exemplo apresenta-se o texto a seguir:

As cidades e a memória: [...] Diomira: Cidade com sessenta cúpulas de prata, estátuas de bronze de todos os deuses, ruas lajeadas de estanho, um teatro de cristal, um galo de ouro que canta todas as manhãs no alto de uma torre"; [...] Isioda: "Na praça, há o murinho dos velhos que vêem a juventude passar, ele está sentado ao lado deles". Os desejos agora são recordações; [...] Zaíra: "A cidade é feita das relações entre as medidas de seu espaço e os acontecimentos do passado" [...] Zora: "Cidade que quem viu uma vez nunca mais consegue esquecer. Mas não deixe, como outras cidades memoráveis, uma imagem extraordinária nas recordações”. Obrigada a permanecer imóvel e imutável para facilitar a memorização Zora definhou, desfez-se e sumiu. Foi esquecida pelo mundo"; [...] Maurília: "a praça idêntica mas com uma galinha no lugar da estação de ônibus, o coreto no lugar da fábrica de explosivos" (CALVINO, 2006, p.11)

Calvino (2006) consegue transpor para o seu texto sentimento e pertencimento do lugar das praças nas cidades, suas próprias simbologias, memórias e significados que as tornam únicas.

Nesse contexto, vale ressaltar também a importância da paisagem para, pois como categoria da investigação geográfica também pode ser analisada de forma significativa, na representação de processos e acumulações históricas no tocante ao estudo sobre as praças. [...] "O espaço desempenha um papel ou uma função decisiva na estruturação de uma totalidade, de uma lógica de um sistema" (LEFÉBVRE, 1976, p.25).

Nota-se que a paisagem é um conjunto de formas naturais e artificiais, um conjunto de objetos que tem idades diferentes, uma herança de diferentes momentos, é objeto de mudança, é uma espécie de marca da história do trabalho e dependem das condições econômicas, políticas e culturais. As ações são parte constituinte da paisagem, a dinâmica da paisagem não apenas se transforma ao modificar-se o sistema material físico, mas ao realizar-se o sistema de ações, parte da visibilidade que caracteriza a paisagem e, também vai além do visível através do imaginário do observador.

A ciência geográfica se interessa na identificação e no entendimento das relações que se criam das relações entre o homem, à sociedade e a natureza. A cidade é uma expressão espacial da evolução social, isto porque é através dessa interação que as sociedades modificam a natureza, para a satisfação de suas necessidades socioeconômicas. As cidades sempre foram alvo de investigação e interesse dos geógrafos, em decorrência das inúmeras transformações que nelas ocorrem. "O espaço pode ser concebido como um ser específico do real, com características e com uma dinâmica própria”. (MORAIS, 1999, p.17).

Segundo Portas (2006) o espaço, enquanto recurso humano limitado e desigualmente distribuído constitui um local de confronto pela sua apropriação, interpretação e utilização por parte dos atores sociais, em regra inseridos em grupos sociais. O espaço por um lado, como o tempo constitui uma das condições e eixos inerentes à sociedade humana, por outro, a organização do espaço comporta a marca da ação humana.

Geografia Ensino \& Pesquisa, v. 18, n.3, p. 27-36, set./dez. 2014

Abordagens geográficas sobre as praças da área central da cidade de Poços de Caldas (MG)
As realidades espaciais constituem não só locais de reprodução social, como também testemunhos da memória colectiva de um agrupamento humano, do seu percurso histórico, das suas vicissitudes e contradições, não só internas como face ao exterior. (PORTAS, 2006, p.187).

É possível afirmar que as praças da cidade de Poços de Caldas se constituem como lugares de patrimônio cultural natural à medida que nesses espaços se estabelecem relações políticas, sociais, culturais e econômicas. Portanto, são espaços dinâmicos que possuem memoria coletiva simbólica e de pertencimento. 


\section{Considerações finais}

As praças, além de conservarem o histórico local, de servir para amenizar os impactos urbanos na área central das cidades, principalmente, naquelas consideradas áreas verdes, estabelecem ainda características diferentes do ambiente da cidade. Preservam além da identidade e cultura local, as referências e características que a tornam única, sejam por apresentar comerciantes ambulantes; bancos para assento; posto policial; pontos de taxi, árvores; fontes; brinquedos; dentre outras características.

O Lugar é constituído, conforme Tuan, como um "espírito", como uma "personalidade". Se o lugar fizer algum "sentido" para as pessoas, certamente será manifestado pela apreciação visual ou estética, como também, pelos sentidos desenvolvidos a partir da relação: homem x lugar, seja ele topofóbico ou topofilico.

Enfim, as praças, em especial as praças centrais da cidade de Poços de Caldas são lugares a serem conservados e recuperados quando necessário, são lugares de realizações culturais, folclóricas e festivas; representam a história do povo do lugar. Ou seja, as praças centrais da cidade de Poços de Caldas podem ser consideradas como um espírito, como uma personalidade, pois é o lugar, dessa cidade, que faz sentido para as pessoas, pela apreciação visual, pelos sentidos que relacionam homem x lugar, tanto para os moradores locais, quanto para os "de fora", os diversos turistas, que passam pela cidade.

A paisagem das praças centrais na cidade de Poços de Caldas representa processos históricos de formas naturais e artificiais que possuem idades diferentes, heranças de diferentes momentos condicionados pelas ações econômicas, políticas e culturais da cidade que foram e, constantemente são capturadas através do imaginário do observador, seja pela visão descomprometida do observador local, ou pela visão atenta e pormenorizada do observador visitante, o turista.

Nessa perspectiva, pode-se direcionar a cidade a se preocupar com a praça na área central da cidade de Poços de Caldas enquanto patrimonial cultural e natural e intangível, pois a paisagem, o lugar, os aspectos históricos, sociais, econômicos e culturais sempre estão em correlação com perspectivas para o futuro. Nela estão representados os desejos, as recordações, a relação entre as medidas de seu espaço e, os acontecimentos do passado de quem viu uma vez e que nunca mais consegue esquecer. Aquelas imagens extraordinárias nas suas recordações imóveis e imutáveis que facilitam a memorização, sem consegui se desfazer e, ou desaparecer.

Assim cabe as praças urbanas serem alvo de constantes reflexões geográficas em virtude das suas transformações que produzem elementos diversos que se interagem, produzindo as complexidades da realidade local.

\section{Referências}

ABREU, Regina. A emergência do patrimônio genético e a nova configuração do campo do patrimônio. In: ABREU, Regina, et.al. (ORGs.) Memória e patrimônio: ensaios contemporâneos. Rio de Janeiro: DP\&A, 2003.

ALVES, Lidiane Aparecida. Os processos socioespaciais da zona periférica do centro: um estudo da área central de Uberlândia (MG). 2011. Dissertação de Mestrado apresentada ao Programa de Pós-Graduação em Geografia da Universidade Federal de Uberlândia- MG.

ARCHELA, Rosely Sampaio. et.al. O lugar dos mapas mentais na representação do lugar. Geografia - Londrina - volume 13 - número 1 - jan./jun. 2004. Disponível em http://www.geo.uel.br/revista.

CALVINO, Italo. As cidades invisíveis. São Paulo: Companhia das letras, 2006.

CORREA, Roberto Lobato. O Espaço Urbano. Editora Ática, Série Princípios, 3 a edição,n. 174, 1995. P.116.

CORRÊA, Roberto Lobato. Espaço: um conceito-chave da Geografia. In. CASTRO, Iná Elias de et. al. (ORGs.) Geografia: conceitos e temas $3^{\circ}$ ed. Rio de Janeiro: Bertrand Brasil, 2001.

Geografia Ensino \& Pesquisa, v. 18, n.3, p. $27-36$, set./dez. 2014

Queiroz, A. M. D.; Santos, R. J.

ISSN 2236-4994 
DRUMMOND, José Augusto, Patrimônios natural e cultural: endereços distintos nos espaços urbanos, rurais e selvagens. In: LUCHIARI, Maria Tereza Paes et.al. (ORGs), Patrimônio natureza e cultura. Campinas. São Paulo. Papirus, 2007.

GONÇALVES, José Reginaldo Santos. O patrimônio como categoria de pensamento. In: ABREU, Regina et.al, (org.), Memória e patrimônio: ensaios contemporâneos. Rio de Janeiro: DP\&A, 2003.

IBGE. Instituto Brasileiro de Geografia e Estatística. Disponível em: <http:/www.ibge.gov.br>. Acesso em junho 2012.

LAUANDE JUNIOR, Francisco de Assis. Brasília: a praça dos três poderes.2008. Dissertação de mestrado da faculdade de arquitetura e urbanismo da Universidade de Brasília-DF.

LEFEBVRE, Henri. Espacio y política. Barcelona: Ediciones Península, 1976. 159 p.

LOPES, Michelly de Lourdes. O comércio varejista em Uberlândia (MG) e sua atuação como agente modificador do espaço urbano: As estratégias da rede Bretas de supermercados. Dissertação de Mestrado. 2012. Pós-Graduação em Geografia da Universidade Federal de Uberlândia- MG.

MORAIS, Antonio Carlos Robert. Geografia: pequena história crítica. São Paulo: Hucitec, 1999.

OLIVEN, Ruben George, Patrimônio intangível: considerações iniciais. In: ABREU, Regina et.al. org. Memória e patrimônio: ensaios contemporâneos; Rio de Janeiro: DP\&A, 2003.

PORTAS, Nuno. Regeneração e projectos urbanos. In. BALSA. Casimiro. Edições Colibri. Relações Sociais de Espaço- Homenagem a Jean Remy. Lisboa. 2006.

SANT'ANNA, Marcia; A face imaterial do patrimônio cultural: os novos instrumentos de reconhecimento e valorização. In: ABREU, Regina, (et.al-orgs.). Memória e patrimônio: ensaios contemporâneos, Rio de Janeiro: DP\&A, 2003.

SANTOS, Cecília Rodrigues dos. Novas Fronteiras e Novos Pactos para o Patrimônio Cultural. Núcleo de Arquitetura do Centro Cultural São Paulo. Guia Cultural do Estado de São Paulo (Fundação Seade e Secretaria da Cultura do Estado, 2001) São Paulo em Perspectiva, 15 (2) 2001.

SANTOS, Milton. A natureza do espaço: técnica e tempo, razão e emoção. $3^{a}$ ed. São Paulo: Hucitec, 2002.

VAZ, Domingos; O urbano e o território: notas sobre algumas questões emergentes. In. BALSA. Casimiro. Edições Colibri. Relações Sociais de Espaço- Homenagem a Jean Remy. Lisboa. 2006.

PORTAS, Nuno. In. BALSA. Casimiro. Edições Colibri. Relações Sociais de Espaço-Homenagem a Jean Remy. Lisboa. 2006. (Ver p. 187).

ROBBA, Fábio; MACEDO, Silvio Soares. Praças brasileiras. São Paulo: EDUSP, 2003.

TUAN, Y-Fu. Espaço e lugar: a perspectiva da experiência. Tradução Lívia de Oliveira. São Paulo: DIFEL, 1983.

VAZ, Domingos; In. BALSA. Casimiro. Edições Colibri. Relações Sociais de Espaço-Homenagem a Jean Remy. Lisboa. 2006. (Ver p. 187).

Geografia Ensino \& Pesquisa, v. 18, n.3, p. 27-36, set./dez. 2014

Abordagens geográficas sobre as praças da área central da cidade de Poços de Caldas (MG)

\section{Correspondência:}

\section{Antonia Marcia Duarte Queiroz}

E-mail: amdqueiroz@yahoo.com.br

Recebido em 11 de agosto de 2013.

Revisado pelo autor em 19 de outubro de 2014.

Aceito para publicação em 10 de novembro de 2014. 